\title{
Research on the Progress of Technologies and Materials and Its Features about Prefabricated Constructions in China
}

\author{
Qiaofeng Qian \\ School Of Architecture \\ South China University Of Technology \\ Guangzhou , China \\ e-mail: 511045168@qq.com
}

\begin{abstract}
Domestic prefabricated construction has developed for a long period, and has attracted more and more attentions. This paper analyzes the progresses it has made in technical and material aspects through history and prospect. Furthermore, the features and advantages are summarized in order to promote the sustainable development of prefabricated construction.
\end{abstract}

Keywords- Prefabricated construction; technology; material; features; sustainable development

\section{THE REVIEW AND EXPECTATION ABOUT PREFABRICATED CONSTRUCTION}

Domestic prefabricated construction refers to those constructions that has using function and whose components are prefabricated in factory and then transported to construction site by using reliable installation method.

The research of prefabricated constructions started from Europe. Early in 17th century, UK and France has began exploring industrialization of construction industry. Till the 1950s, prefabricated constructions enjoyed a rapid development due to the enormous damage caused by the Second World War that it brought an unprecedented tension of housing. The western countries gained a lot experiences during the long term search and developed mutual industry standers. By now housing under five-orsix stories are usually prefabricated constructions in western countries, which make up $35 \%$ to $40 \%$ of concrete structure constructions. In the early 20th century, PCI was set up in America to make industry standards, which has stimulated the development of prefabricated constructions. And now it makes up $35 \%$ in concrete structure constructions. In Japan, as they combined the advantages of European countries and the U.S. with its own actual construction environment, its prefabricated technology ranked top in the world. They apply the prefabricated construction idea to earthquake oriented design of highrise and super high-rise buildings successfully. What's more, they make unprecedented development in prefabricated constructions. Now the percentage of prefabricated constructions in concrete structure constructions is more than $50 \%$.

It is not late for our country to begin explore prefabricated construction. From 50s to 80s last century, varies pre-cast concrete floor, hollow floor and roof girder were largely used. According to incomplete statistics, prefabricated constructions made up 35\% in the whole constructions by 1985 . However, as quality reduction and unprofessional install of building members, they have been replaced by full cast-in-situ structure with the development of cast-in-site technique. This leads the level of domestic prefabricated construction fall behind the advanced international standard $\mathrm{s}$, at the same time, industry and technical norms are absent. Full cast-in-situ structure constructions made outstanding contribution in the stage of low level of labor cost and construction level; however, it also brought some problems such as environmental pollution, noisy, wasting of resources and insecurity. With the need of green environmental protection and labor cost are increasing after 21 century, traditional form of construction work is hard to continue and prefabricated construction are more and more attractive as an advanced construction method.

The national building industry conference which is held in late 2013 proposed that in order to deepen the reform of construction industry, increasing the modernization of construction industry is the key emphasis in work. Standard system of architectural industrialization is under making by Ministry of Housing and Urban-rural Development as well as other documents such as technical regulations of prefabricated concrete structure is actively carried out. We can forecast that prefabricated construction is facing a good time as an important part of construction industry.

\section{THE PROGRESSES ON TECHNICAL AND MATERIAL OF PREFABRICATED CONSTRUCTION}

Traditional prefabricated constructions usually perform poorly and have poor anti-seismic capability; they also have unitary formation and large densities with heavy weight and low ecological benefits. However, these technical barriers will be conquered through technological and material innovation with the development of social economy and scientific level. There are following aspects.

\section{A. Innovation of technology system}

1) Technical innovation of main body.

The progress of main body refers to the innovation of prefabricated concrete structure. Aiming at the current problems of prefabricated constructions, large panel structure and brick structure, superposed beam, 
superimposed sheet, prefabricated plug-in wallboard, new connector, modular box technology and node technique are used to raise the level earthquake resistance and holistic behavior, finally compose a inter=grated architectural technology system.

2) Technical innovation of decoration and finish.

New type of prefabricated construction brings in the idea and method of foreign industrialization to make a general system inside the building. There is no need of secondary operation due to industrialization and modularization. Combined unit bathroom, integration type kitchen with collective system, an integral forming decoration is realized

There is a second time decoction when main body and retaining structure are finished in traditional mode of construction. New prefabricated construction is a common used system inside buildings by bring in industrialization abroad.

3) Technical innovation of facility integration system.

New type of prefabricated construction coordinates the plan, construction and management of whole building lifecycle. Hence, in early stage of design, water supply, exhaust, electrical, ventilate and heating system could all get involved. That means the design and construction of all facilities could finish integrate one time. In this way, we achieve many things at one stroke with the need of routine maintenance and upgrade of facilities and line pipes.

\section{B. Usage of new materials}

To meet the need of new prefabricated construction, structural and wall material are under renewing. Being more environmental protection and energy conservation, the materials are changing into fabricated forming plate from brickwork, with lighter, higher intensity and multifunction. There are the following new type boards, composite core wall with keel sheet, reinforced compressed straw building slabs, color plate with thermal insulation material, honeycomb composite board with core material and wood wool slab. These material can not only meet the function need of modern constructions, but also support the development of new type of prefabricated constructions.

\section{THE FEATURES OF NEW TYPE OF PREFABRICATED CONSTRUCTIONS}

\section{A. Architectural designs}

They have advanced design ideas and compatibility. New type of prefabricated construction aim to prefabricate building components in appointed factory and transport to construction site to precast. It is not limit to pour in the site, meanwhile, achieve compound construct of steelwork, concrete and new materials. This is a more suitable production mode of modern building design idea

New type of prefabricated constructions has a flexible structural system with strong changeability. With the raise of construction structure and of the components, new type of prefabricated constructions can separate structural support and infill system, which guarantee the durability of the support bodies and variability of filling bodies. By this way, users can easily change according to practical function. This is an improvement to too many bearing walls, too small divisions, too small bays and the inner space cannot cut apart flexible. (Figure 1)

Production under modulus control shows a high level of industrialization. Separating construction into supporting system and filling system, both of which are further divided into different components for the purpose of standard design and production, which is beneficial to standardized modular architecture space and building facade repeatability of large-scale production and construction.

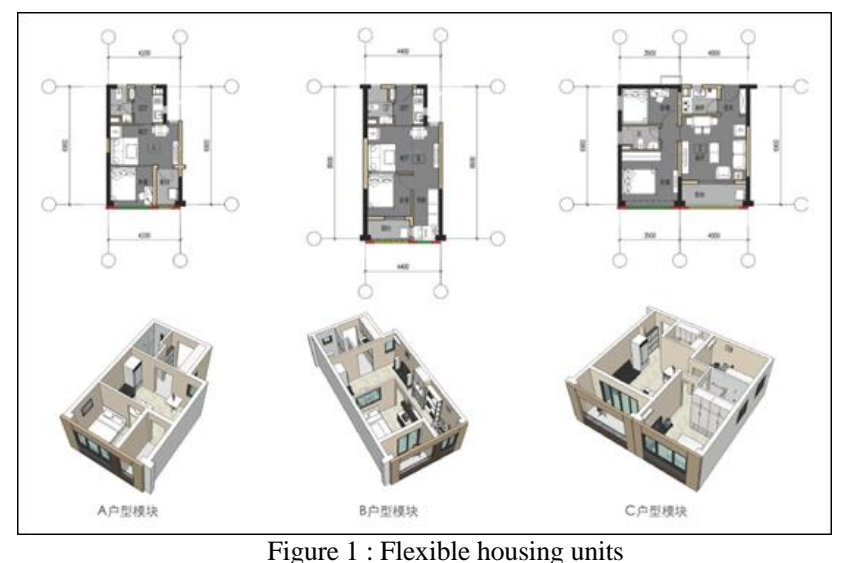

\section{B. Engineering quality}

Material property and anti-crack are strong. Prefabricated constructions use new light material, and have superior performance on sound insulation, fireresistant, heat preservation, antiseptic and damp proof. As reduce the self-weight, the anti-seismic property is also increased. (Figure 2)

Construction featuring industrialization demonstrates a high level of integrity. Building components under the means of precast shall be installed through the integrated control mode and under the professional guidance of connection in order to maximize the overall performance of the construction, at the same time, construction quality can be guaranteed in spite of different construction levels. (Figure 3)

Excellent ornamental effect. Precast cladding can use all sorts of veneer in advance and cooperate with the architectural design of embedded ceramic tile, stone, water mold, etc; Controlling of the quality of the prefabricated wall becomes more convenient and the appearance upgraded. Ornament engineering can be conducted without refurbishment program so that the quality and effect are guaranteed. (Figure 4)

Integration of all facilities. In the process of construction, this new type of fabricated constructing can conduct the pipeline of water, air conditioner, fresh air, heating, electrical equipment etc. through preinstallation .By doing so the problem of installation error, leaking and touch deficiency can be avoided and construction efficiency as well as quality shall be improved, which are beneficial to the construction of a cozier and cleaner house.Facilities and equipment system unified. (Figure 5) 

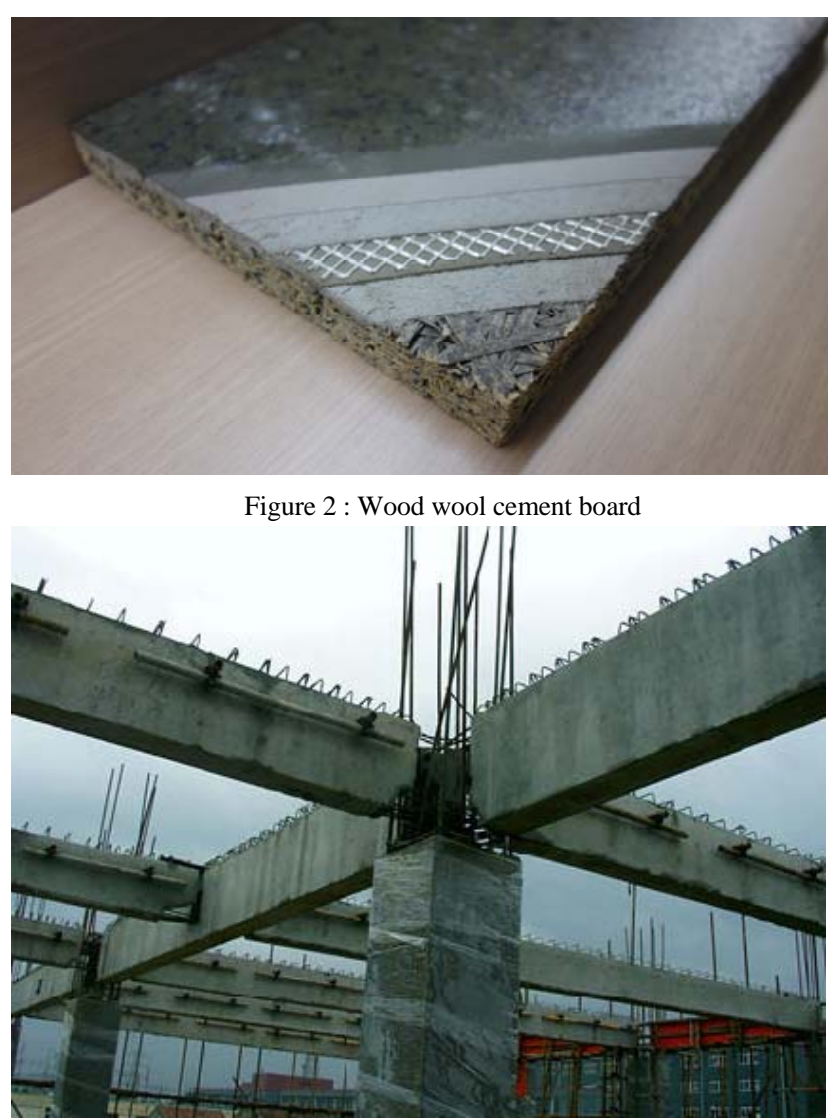

Figure 3 : Connection technology

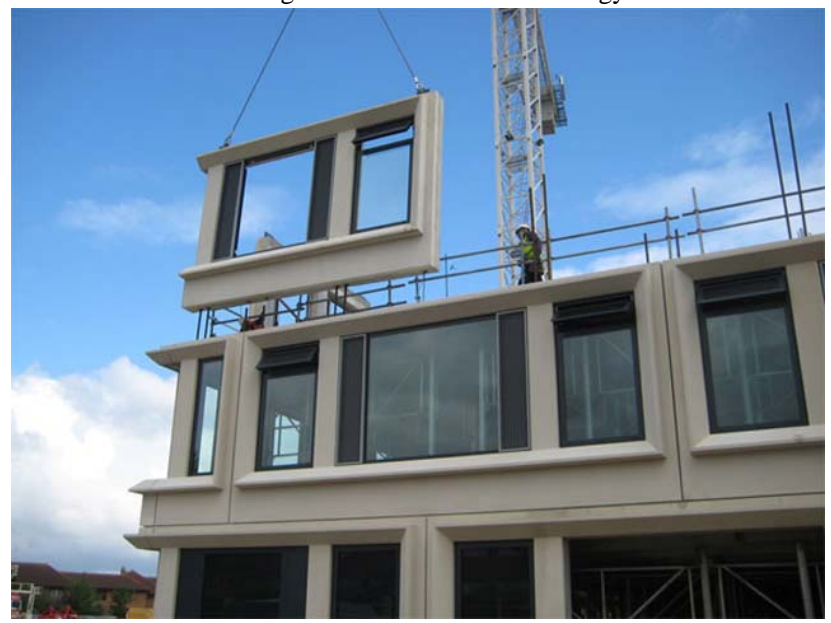

Figure 4 : Precast facades

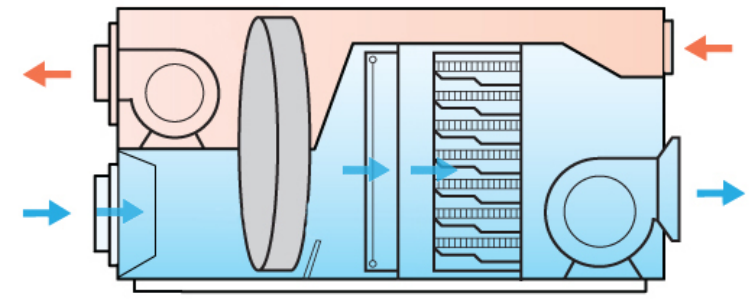

Figure 5 : Preset new trend in T30 Hotel by Broad Group

\section{Construction period}

Prefabricated components are mechanized produced. With less cast-in-place ways, it only needs to pour component node. This makes it faster and takes short construction period. This reduces workload and lower construction difficulty; workers can work in special weather. Not only the time and cost of the project is saved, but also the schedule of construction is guaranteed and reduces the cost. (Figure 6)

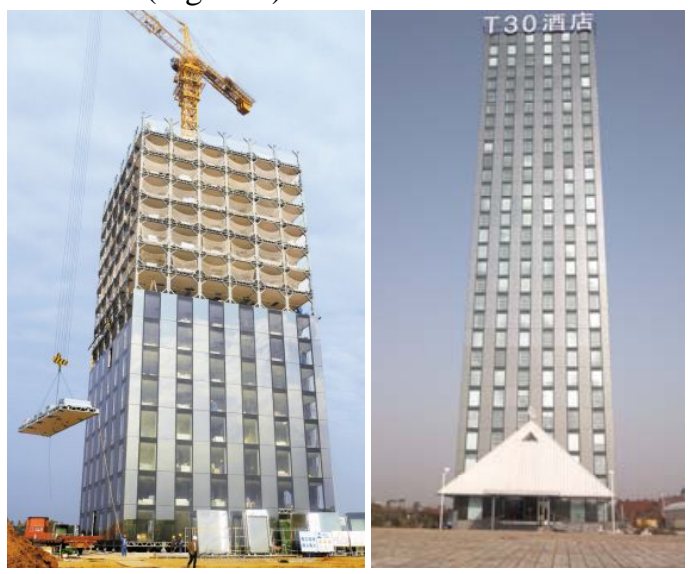

Figure 6 : T30 Hotel which complete within 30 days

\section{Economic interests}

In developed areas and countries such as Western Europe, North America and Japan, the cost of prefabricated construction has been effective control. According to the statistics, compared with traditional buildings, $25 \%$ to $30 \%$ labor cost is reserved and building cost reserved $15 \%$ to $20 \%$. However, as we are still searching in our country, prefabricated residential rate is only at $15 \%$ to $20 \%$, the building cost is superior to traditional cast-in-place buildings. However, with the encouragement of government and raise of industry level, progresses have been made in policy, design, transportation and installation. Aiming at Europe and the United States, the goal of lower the cost largely will be achieved in the future.

\section{E. Environment protection and energy saving}

The production way of prefabricated construction saves a lot of master plates and scaffolds reduce usage of wood, which reduce cost as well as protect our country's forest resources. This way produces fewer productions of noise, smoke and garbage. What's more, precast façade and panel have preserved heat and separated water to avoid destroys of construction site. Also, it is good to keep warm and conserve energy.

\section{SUMMARY}

With the construction system revolution and the expansion of building scale, the modernization of construction industry imperative, and this trend will promote the sustainable development of prefabricated construction worldwide. Progresses are made step by step, we have to be clear about the advantages and disadvantages of the technologies of prefabricated construction in this period and popularize fitness building types. We can believe that the potential of modern construction industry will reveal with the development of the technique, which will bring a revolution of Chinese construction industry. 


\section{REFERENCES}

[1] Gu Changtai, It is imperative to develop modern construction industry [J].Engineering Construction, 2014, 08:8-9.

[2] Li Bin, The future and development of domestic prefabricated constructions $[\mathrm{J}]$. Science and Technology Information of China, 2014, 07:114-115.

[3] Wang Qian, Mao Xiaofeng. A brief introduction of the development of prefabricated constructions. [J]. Scientific and Technological Information, 2012, 21:354+381.

[4] Zhang Shoufeng. Housing industrialization and PC structural system [J] Urban Residential, 2014, 10:38-40.

[5] Jiang Qinjian. Summary of the development prefabricated concrete constructions domestic and overseas [J]. Construction Technology, 2010, 12:1074-1077.

[6] Ye Ming, Wu Jieqing, Some thoughts of impelling the development of new construction industrialization, [J]. Housing Industry, 2013, Z1:11-14.

[7] Wang Ruiqiang, Prefabricated constructions [J]. Shanxi architecture, 2013, 22:95-96.

[8] Zhang Yiquan, The economic benefits of building industrialization [J]. Anhui science and technology, 2013, 10:36-38.

[9] He zhengkai, The summary and exploration about the development and respect of prefabricated constructions, [A]. Construction technology and management organization ,2014:4. Architectural Technology and Management Conference proceedings [C]. Construction technology and management Committee. : 2014:2.
[10] Huang Ling, Zhang Dehai, Tao Shuai, applied significance of prefabricated security housing [A].Shenyang Municipal Party Committee, the People's Government of Shenyang. The 9th Shenyang Annual Science Scholar Conference Proceedings (Information Science and Engineering) [C]. Shenyang Municipal Party Committee, the People’s Government of Shenyang. : 2012:3.

[11] Zheng Kai, Chen Xuhe. The practical prospect of bamboo based panel in construct of prefabricated constructions [J]. Word Bamboo and Rattan, 2006, 01:1-5.

[12] Zou Liang. The practice and worries about building industrialization-He Fei Binhu garden project. [J]. Chinese and Overseas Architectures. 2013, 09:68-69.

[13] Zhu Chuandi, Hua Yong. History Review and prediction of precast reinforced concrete buildings. [J]. Building Block and Block Building, 2014, 06:4-6+8.

[14] Zhang Jichao, Chen Jiefeng, Xu Yong, Wang Keyi, Zhuang Yuhai. Technology study about new type of prefabricated constructions' frame structure. [J] Architectural Structure, 2013, S1:1355-1357.

[15] Chen Jiefeng, The research and use of new type integrally prefabricated frame constructions [D], Guangzhou University, 2013

[16] Jiang Qinjian, Economic analysis of high-rise pre-cast concrete housing [J], Housing Industry, 2013, Z1:23-24.

[17] Zhangye, Advanced technology of architectural design industry: Industrialized Housing Design [J], China Investigation Design, 2014, 12:47-49.. 